\title{
Partial Pressures in Thermodynamics of Classical Fluid Mixtures
}

\author{
Vít Samohýl, Ivan Samohýl, Petr Voňka \\ Department of Physical Chemistry, Institute of Chemical Technology, Prague, \\ Technická 5, 16628 Prague 6, Czech Republic \\ ivan.samohyl@vscht.cz, petr.vonka@vscht.cz (corresponding author)
}

\begin{abstract}
In the rational thermodynamics of most usual nonequilibrium "classical" fluid mixtures it has been proposed the "thermodynamic" partial pressure which generalize traditional definitions and merge together in an ideal gas mixture. In this paper, these thermodynamic partial pressures are calculated for a (real) gas mixture of methane-ethane-carbon dioxide and a liquid mixture of lithium hydroxide in water. The results are compared with those obtained using the classical formulations of partial pressures calculated in these mixtures as well.
\end{abstract}

Key words: Gas mixture, Irreversible thermodynamics, Liquid mixture, Partial pressure, Rational thermodynamics, Thermodynamics of mixtures

\section{Introduction}

In the classical thermodynamics of mixtures composed of $n$ constituents (components of mixture) $\alpha=1, \ldots, n$ partial pressures are rarely used. However when they are used, the following two classical formulations are typically applied to gas mixtures, even chemically reacting ones:

A. (Partington 1949) p. 609: Partial pressure $P_{\alpha}^{A}$ of any gas $\alpha$ is the pressure this gas would exert if it alone occupied the total volume of the mixture at the same temperature.

B. (Prausnitz et al. 1999) p. 584: Partial pressure $P_{\alpha}{ }^{B}$ of constituent $\alpha$ in an $n$-constituent mixture is

$$
P_{\alpha}^{B}=x_{\alpha} P, \alpha=1, \ldots, n
$$

where $x_{\alpha}$ is the molar fraction of $\alpha$ in the considered mixture at the (total) pressure $P$.

While both of these definitions are used for mixtures of real gases, they generally do not give the same results. For example, in case A the sum of the partial pressures $\left(\sum_{\alpha=1}^{n} P_{\alpha}^{A}\right)$ need not be equal to the total pressure of the mixture $P$, i.e. Dalton's law is generally invalid (see Tables and Figures below for examples). However in the case of ideal gas mixtures both definitions do give the same result, i.e. Dalton's law is valid. For this reason the partial pressures are most often used in a mixture of (at least approximately) ideal gases (Samohýl and Voňka 2006). In principle, these definitions may also be used for liquid mixtures, but the application of definition A is limited by either the low compressibility or nonexistence of constituents as pure liquids (cf. below).

Apart from classical thermodynamics, partial pressures, or, more generally, partial stress tensors, have also been used in nonequilibrium thermodynamics (de Groot and Mazur 1962), (Truesdell and Toupin 1960), particularly in the theory of rational thermodynamics (Truesdell 1984, 1968), (Müller 1968, 1985). Using this theory, (Samohýl 1982, 1987, $1975 \mathrm{a}, 1975 \mathrm{~b}$ ) already proposed a concept for partial pressures, termed thermodynamic partial pressure (see Eq. (5)). This can be applied to common fluid mixtures, the "classical" ones, by which we mean the most used fluid mixture with linear transport relations (newtonian with Fourier and Fick laws) possibly chemically reacting, with local equilibrium (i.e. usual thermodynamic relations are valid). In special cases (e.g. low pressure) this concept gives the same results as the formulations for classical partial pressures. In the following Section we briefly describe this conception, together with the reasons for it, and in next Section we demonstrate the application of thermodynamic partial pressures to selected gas and liquid mixtures.

\section{Partial Pressures in Rational Thermodynamics}

In recent decades, continuum thermodynamics of mixtures has developed to also encompass irreversible processes (de Groot and Mazur 1962), (Truesdell 1984). Continuum thermodynamics uses some partial properties (i.e. properties concerning mixture constituents; because of the use of momentum balances we prefer specific quantities rather than molar ones) that generally form fields, i.e. functions of position and time. Such fields include partial densities $\rho_{\alpha}$ (in chemistry termed mass concentrations - mass of constituent $\alpha=1, \ldots, n$ per unit volume of a mixture composed of $n$ constituents). Partial densities enable us to define the density of a mixture $\rho$ and to express its composition using the mass fraction $w_{\alpha}$ : 


$$
\begin{aligned}
& \rho \equiv \sum_{\alpha=1}^{n} \rho_{\alpha}, \quad w_{\alpha} \equiv \rho_{\alpha} / \rho, \\
& \alpha=1, \ldots, n, \quad \sum_{\alpha=1}^{n} w_{\alpha}=1
\end{aligned}
$$

Theories of this type can be applied to rational thermodynamics (Truesdell and Toupin 1960), (Truesdell 1984, 1968), (Müller 1968, 1985), (Samohýl 1982, 1987), in which some partial properties can be used a priori as primitive concepts. Such properties include not only partial specific internal energies $u_{\alpha}$ and entropies $s_{\alpha}$, but also partial stress tensors $\boldsymbol{T}_{\alpha}$, which were introduced (Truesdell and Toupin 1960) Sect. 215 to describe the surface forces in the momentum balance of each constituent $\alpha$. Rational thermodynamics describes the continuum thermomechanics of different constitutive (or material) models of pure solids, fluids, etc. and their mixtures (Truesdell 1984), (Müller 1985), (Samohýl 1982). Primarily it is applied to mixtures of fluids (i.e. gases or liquids) because, under certain limited conditions, it encompasses the classical thermodynamics of mixtures (primarily equilibrium and uniform (homogeneous) theories). The classical thermodynamic structure (i.e. "local equilibrium") is valid even when transport phenomena (e.g. viscosity, heat conduction, diffusion) and chemical kinetics are in progress (Müller 1968, 1985), (Samohýl 1982, 1987, 1975a, 1975b). In fluid mixtures partial stress tensors take the typical form, see, e.g. (Samohýl 1987) Eq. 27.1.

$$
\boldsymbol{T}_{\alpha}=-P_{\alpha} \mathbf{1}+(\text { nonequilibrium stress })_{\alpha}, \alpha=1, \ldots, n
$$

where $P_{\alpha}$ is the partial pressure of a constituent $\alpha$ and $\mathbf{1}$ is the unit tensor. To stress the difference from the classical definitions $\mathrm{A}$ and $\mathrm{B}$ above, we hereinafter denote $P_{\alpha}$ as thermodynamic partial pressures. The partial nonequilibrium stresses in (3) primarily result from viscosity, but may additionally be influenced by chemical reactions, see (Samohýl 1987) Sect. 22, for details.

In the commonly used model of fluid mixtures with linear transport properties (e.g. Fourier, Fick and Newtonian laws are valid), and even with nonlinear chemical kinetics (Samohýl 1982, 1987, 1975a), thermodynamic partial pressures only depend on the (abso-lute) temperature $T$ and the densities $\rho_{\gamma}, P_{\alpha}=\widehat{P}_{\alpha}\left(T, \rho_{1}, \ldots, \rho_{\mathrm{n}}\right)=$ $=\widehat{P}_{\alpha}\left(T, \rho_{\gamma}\right), \alpha, \gamma=1, \ldots, n$. (We use this shorter notation in the following, i.e. $P_{\alpha}$ depends on all partial densities $\rho_{\gamma}, \gamma=1, \ldots, n$. Similarly, e.g. in (6), the specific volume $v$ depends not only on $T$ and $P$, but also on all independent mass fractions $w_{\beta}, \beta=1, \ldots$, $n-1$. Note also that the use of an overhead symbol, e.g. $\hat{P}_{\alpha}, \widetilde{v}, \hat{v}_{\alpha}$, means functions with corresponding values $P_{\alpha}, v, v_{\alpha}$, cf. Eqs. (6), (7).)
Moreover, the thermodynamic mixture pressure $P$ defined as

$$
P=\widehat{P}\left(T, \rho_{\gamma}\right) \equiv \sum_{\alpha=1}^{n} P_{\alpha}
$$

is the same as that appearing in the structure of classical thermodynamics (local equilibrium, implying e.g. Gibbs equations, is proved in this model). The structure of rational thermodynamics also permits the definition of the following (specific) quantities: partial free energies $f_{\alpha}=u_{\alpha}-T s_{\alpha}$, free energy of a mixture

$$
f=\sum_{\alpha=1}^{n} w_{\alpha} f_{\alpha}=\widehat{f}\left(T, \rho_{\gamma}\right)
$$

and chemical potentials $g_{\alpha}=\partial \rho \widehat{f} / \partial \rho_{\alpha}$. These quantities depend on temperature and densities (such as $\widehat{f}, \widehat{P}$ above), see (Samohýl 1982, 1987, 1975a, 1975b), (Samohýl and Šilhavý 1990) for details. In non-reacting mixtures the thermodynamic pressure $P$ is equal to the actual (measured) pressure, but need not be the same in chemical kinetics (cf. discussion of (3)). It can be also proved, see (Samohýl 1987) Eqs 22.39, 23.1, (Samohýl 1975) Eq. 52, (Samohýl 1975b) Eq. 1, that $g_{\alpha}=f_{\alpha}+P_{\alpha} / \rho_{\alpha}$. The classical counterpart of this expression provides the motivation for the following relation between thermodynamic partial pressures $P_{\alpha}$ and thermodynamic mixture pressure $P$

$$
P_{\alpha}=\rho_{\alpha} v_{\alpha} P, \alpha=1, \ldots, n
$$

which may be understood as the definition of the partial specific volume $v_{\alpha}$ of a constituent $\alpha$. Indeed, from (4), in accordance with the expected properties, we obtain the specific volume $v$ of a mixture

$$
v=1 / \rho=\sum_{\alpha=1}^{n} w_{\alpha} v_{\alpha}=\tilde{v}\left(T, P, w_{\beta}\right), \quad \beta=1, \ldots, n-1
$$

By the inversion of (4) and with (2), the independent variables $T, P, w_{\beta}$ may be used (Samohýl 1982, 1987), (Samohýl and Šilhavý 1990) instead of $T, \rho_{\gamma}$, and therefore, for example, we can obtain

$$
v_{\alpha}=\hat{v}_{\alpha}\left(T, \rho_{\gamma}\right)=\tilde{v}_{\alpha}\left(T, P, w_{\beta}\right), \quad \alpha=1, \ldots, n
$$

All of these relations are valid for the fields of this model, even when it is out of equilibrium but the partial quantities are not unique (except in the case of $g_{\alpha}$ and mixture properties, such as $f, v$ ), see (Samohýl 1982, 1987, 1975a, 1975b). However, using a basic property of all mixture balances (mass, momentum and their moment, energy and entropy inequality) called mixture (or form) invariance (Samohýl 1982, 1987, 1975b), (Samohýl and Šilhavý 1990), this non-uniquiness may be removed, and, for example, partial specific volumes may be calculated from specific mixture volume (6) as follows 


$$
\begin{gathered}
v_{n}=v-\sum_{\beta=1}^{n-1} w_{\beta}\left(\partial \tilde{v} / \partial w_{\beta}\right) \\
v_{\beta}=v_{n}+\partial \tilde{v} / \partial w_{\beta}, \quad \beta=1, \ldots, n-1
\end{gathered}
$$

In a uniform (homogeneous) fluid mixture the formulas (8), (9) are equivalent to $v_{\alpha}$ expressed as derivatives of the extensive volume of the mixture according to the mass of each constituent $\alpha=1, \ldots$, $n$ at a constant $T, P$, see, e.g. (Samohýl and Šilhavý 1990) Eq. 8.41 or (Samohýl 1987) Eq. 23.62.

In fact, if we use molar quantities instead of specific ones, these formulas become, in effect, the classical ones. Namely, the counterparts of $\rho_{\alpha}, \rho, w_{\alpha}$ are molar concentrations $c_{\alpha}$, molar density $c$ and molar fractions $x_{\alpha}$ as given by:

$c_{\alpha}=\rho_{\alpha} / M_{\alpha}, \quad c \equiv \sum_{\alpha=1}^{n} c_{\alpha}, \quad x \equiv c_{\alpha} / c, \quad \sum_{\alpha=1}^{n} x_{\alpha}=1$

where $M_{\alpha}$ is the molar mass of the corresponding constituent $\alpha=1, \ldots, n$. The classical partial molar volumes $V_{\alpha}$ are given by (cf. Rem. 2)

$V_{\alpha}=v_{\alpha} M_{\alpha}=\overline{V_{\alpha}}\left(T, P, x_{\beta}\right), \alpha=1, \ldots, n ; \beta=1, \ldots, n-1$

and the molar volume $V$ of a mixture is given by

$$
1 / c=V=\sum_{\alpha=1}^{n} x_{\alpha} V_{\alpha}=\bar{V}\left(T, P, x_{\beta}\right)=M v
$$

The (classical) independent variables $T, P, x_{\alpha}$ here follow from

$$
w_{\alpha}=x_{\alpha} M_{\alpha} / M, \quad M \equiv \sum_{\alpha=1}^{n} x_{\alpha} M_{\alpha}
$$

where $\mathrm{M}$ is the average molar mass (depending on composition). Note also that (Samohýl 1987) Sect. 23

$$
\rho_{\alpha} v_{\alpha}=c_{\alpha} V_{\alpha}, \quad \alpha=1, \ldots, n
$$

From the derivative of (12), we obtain the molar counterparts of (8), (9)

$$
\begin{gathered}
V_{n}=V-\sum_{\beta=1}^{n-1} x_{\beta}\left(\partial \bar{V} / \partial x_{\beta}\right) \\
V_{\beta}=V_{n}+\partial \bar{V} / \partial x_{\beta}, \quad \beta=1, \ldots, n-1
\end{gathered}
$$

Again, in a uniform (homogeneous) mixture formulas (15), (16) are equivalent to the classical thermodynamic definitions of partial molar volumes (i.e. to derivatives of extensive volume, with respect to the moles of each constituent at a constant T, $P$ (Prausnitz et al. 1999).

For a mixture of ideal gases, it holds that (Samohýl and Voňka 2006).

$$
\rho_{\alpha} v_{\alpha}=c_{\alpha} V_{\alpha}=x_{\alpha}, \quad \alpha=1, \ldots, n
$$

and, therefore (in gases), it follows that, in the case of low pressure limit, all definitions of partial pressures are the same, $P_{\alpha}=P_{\alpha}^{A}=P_{\alpha}^{B}$.

From these formulas it can be seen that by knowing the state equations of a mixture in molar or mass units, i.e. $V=\bar{V}\left(T, P, x_{\beta}\right)$ or $v=\tilde{v}\left(T, P, w_{\beta}\right)$, we can calculate either the partial molar or specific volumes (at a given pressure $P$ and composition) using (15), (16) or (8), (9) respectively. The corresponding thermodynamic partial pressures can then be calculated using (5) and (14). The necessary partial densities or concentrations follow from (2) or (10) respectively.

\section{Partial Pressures in Gas and Liquid Mixtures}

In this Section we demonstrate the calculation of thermodynamic partial pressures for selected gas and liquid systems, and compare them with the classical definitions $\mathrm{A}$ and $\mathrm{B}$.

For the calculation of thermodynamic partial pressures in gas mixtures we used a ternary mixture of methane, ethane and carbon dioxide at $320 \mathrm{~K}$ and at pressures up to $10 \mathrm{MPa}$. The state equation of this mixture, determined by (Hou et al. 1996), permits the calculation of thermodynamic partial pressures, as well as of the classical partial pressures of types $\mathrm{A}$ and $\mathrm{B}$.

For the calculation of thermodynamic partial pressures in liquid mixtures we used a water solution of lithium hydroxide, for which densities as a function of mass fractions were given by (Söhnel and Novotný 1983) at $20^{\circ} \mathrm{C}$ and atmospheric pressure. We compared the calculated partial pressures with classical partial pressures of type B (as was already noted, model A cannot be applied in this case).

All results are presented in Tables 1-4 and Figures 1 and 2 below. For the ternary gas mixture $\mathrm{CH}_{4}(1)-\mathrm{C}_{2} \mathrm{H}_{6}(2)-\mathrm{CO}_{2}(3)$, the state equation (Hou et al. 1996) takes the form of the following virial equation for pressure $P$ as a function of molar volume $V$ :

$$
P=\mathrm{R} T / V+B \mathrm{R} T / V^{2}+C \mathrm{R} T / V^{3}=P\left(T, V, x_{\beta}\right)
$$

where $\mathrm{R}$ is the gas constant, and $B$ and $C$ are the second and third virial coefficients. These coefficients depend not only on temperature $T$ (which is fixed and not stated in the following), but also on the molar fractions $x_{\beta}=x_{1}, x_{2}\left(x_{3}=1-x_{1}-x_{2}\right)$ as follows (upper indices represent powers)

$$
\begin{aligned}
& B=B_{11} x_{1}^{2}+B_{22} x_{2}^{2}+B_{33} x_{3}^{2}+2 B_{12} x_{1} x_{2}+ \\
& +2 B_{13} x_{1} x_{3}+2 B_{23} x_{2} x_{3} \\
C & =C_{111} x_{1}^{3}+C_{222} x_{2}^{3}+C_{333} x_{3}^{3}+3 C_{112} x_{1}^{2} x_{2}+ \\
+ & 3 C_{113} x_{1}^{2} x_{3}+3 C_{223} x_{2}^{2} x_{3}+3 C_{122} x_{1} x_{2}^{2}+ \\
+ & 3 C_{133} x_{1} x_{3}^{2}+3 C_{233} x_{2} x_{3}^{2}+6 C_{123} x_{1} x_{2} x_{3}
\end{aligned}
$$


Tab. 1. Pressure $P=5 \mathrm{MPa}$, temperature $T=320 \mathrm{~K}$, molar volume $V=440.1 \mathrm{~cm}^{3} / \mathrm{mol}$, compresibility factor $P V / \mathrm{R} T=0.82702$, virial coefficients $B=-86.37 \mathrm{~cm}^{3} / \mathrm{mol}, C=4510 \mathrm{~cm}^{6} / \mathrm{mol}^{2}$, pressures in $\mathrm{MPa}$, sum $=$ sum of pressures.

\begin{tabular}{lcccc}
\hline Constituents & $\mathrm{CH}_{4}(1)$ & $\mathrm{C}_{2} \mathrm{H}_{6}(2)$ & $\mathrm{CO}_{2}(3)$ & sum \\
\hline molar fractions $x_{\alpha}$ & 0.3000 & 0.3000 & 0.4000 & ----- \\
partial molar volumes $V_{\alpha} \mathrm{cm}^{3} / \mathrm{mol}$ & 522.3 & 374.1 & 428.0 & ----- \\
thermodynamic partial pressures $P_{\alpha}$ & 1.780 & 1.274 & 1.946 & 5.000 \\
A partial pressures $P_{\alpha}^{A}$ & 1.772 & 1.625 & 2.197 & 5.594 \\
B partial pressures $P_{\alpha}^{B}$ & 1.500 & 1.500 & 2.000 & 5.000 \\
\hline
\end{tabular}

Tab. 2. Pressure $P=10 \mathrm{MPa}$, temperature $T=320 \mathrm{~K}$, molar volume $V=173.4 \mathrm{~cm}^{3} / \mathrm{mol}$, compresibility factor $P V / \mathrm{R} T=0.65195$, virial coefficients $B=-86.37 \mathrm{~cm}^{3} / \mathrm{mol}, C=4510 \mathrm{~cm}^{6} / \mathrm{mol}^{2}$, pressures in $\mathrm{MPa}$, sum $=$ sum of pressures.

\begin{tabular}{|c|c|c|c|c|}
\hline Constituents & $\mathrm{CH}_{4}(1)$ & $\mathrm{C}_{2} \mathrm{H}_{6}(2)$ & $\mathrm{CO}_{2}(3)$ & sum \\
\hline molar fractions $x_{\alpha}$ & 0.3000 & 0.3000 & 0.4000 & ----- \\
\hline partial molar volumes $V_{\alpha} \mathrm{cm}^{3} / \mathrm{mol}$ & 273.4 & 102.9 & 151.3 & ---- \\
\hline thermodynamic partial pressures $P_{\alpha}$ & 4.734 & 1.780 & 3.486 & 10.000 \\
\hline A partial pressures $P_{\alpha}^{A}$ & 4.352 & 3.466 & 4.800 & 12.419 \\
\hline B partial pressures $P_{\alpha}^{B}$ & 3.000 & 3.000 & 4.000 & 10.000 \\
\hline
\end{tabular}

This state equation can also describe pure substances (e.g. $\mathrm{CH}_{4}(1)$ when $x_{1}=1$ and $x_{2}=x_{3}=0$, see (23) below) and binary mixtures (e.g. $\mathrm{CH}_{4}(1)-\mathrm{CO}_{2}(3)$, see (25), (26), (27) below).

The values of the second and third virial coefficients $B\left(\mathrm{~cm}^{3} / \mathrm{mol}\right)$ and $C\left(\mathrm{~cm}^{6} \mathrm{~mol}^{-2}\right)$ used for our mixture at $320 \mathrm{~K}$ are (Hou et al. 1996)

$$
\begin{aligned}
B_{11}=-35.17 & , B_{22}=-159.42, B_{33}=-104.54, \\
B_{12}=-76.71, & B_{13}=-54.02, \quad B_{23}=-105.65 \\
C_{111}= & 2229, C_{222}=9692, C_{333}=4411, \\
C_{112}= & 3594, C_{113}=2641, C_{122}=5902, \\
C_{133}= & 3195, C_{223}=6963, C_{233}=5075, \\
C_{123} & =4204
\end{aligned}
$$

Firstly, using (18), we calculated the molar volume $V$ for each given pressure $P$ and composition (given by $x_{1}, x_{2}$ ). The state equation (18) implicitly contains $V=\bar{V}\left(T, P, x_{\beta}\right)$, and therefore it holds that the derivatives are given by $\partial \bar{V} / \partial x_{\beta}=-\left(\partial P / \partial x_{\beta}\right) /(\partial P / \partial V), \beta=1,2$. Then, using (15), (16) for $n=3$, we calculated partial molar volumes $V_{\alpha}(\alpha=1,2,3)$ for each given (total) pressure and composition. Next, (10), (12) were used to calculate $c_{\alpha}$. Finally, using (5), (14), the thermodynamic partial pressures $P_{\alpha}$ were calculated at total pressure $P$. The results are displayed in Table 1 . For comparison purposes, we also calculated the classical partial pressures (see also Table 1):

To obtain classical partial pressures A, denoted $P_{\alpha}^{A}$, we considered $1 \mathrm{~mol}$ of a mixture, i.e. the molar vol- ume $V$ at a given temperature $(T=320 \mathrm{~K})$, pressure $P$ and composition $x_{1}, x_{2}$ (molar fraction of $\mathrm{CH}_{4}(1)$, $\mathrm{C}_{2} \mathrm{H}_{6}(2)$; for $\mathrm{CO}_{2}(3)$ is $\left.x_{3}=1-x_{1}-x_{2}\right)$. According to definition $\mathrm{A}$, the classical partial pressure $P_{\alpha}^{A}$ of $\mathrm{CH}_{4}(1)$ is equal to the pressure of pure $\mathrm{CH}_{4}$ given by (18) (where $B=B_{11}, C=C_{111}$ because here $x_{1}=1$, $\left.x_{2}=x_{3}=0\right)$, so that the molar volume equals $V / x_{1}$. The same applies for other pure constituents. Therefore it holds:

$$
\begin{aligned}
& P_{\alpha}^{A}=\mathrm{R} T /\left(V / x_{\alpha}\right)+B_{\alpha \alpha} \mathrm{R} T /\left(V / x_{\alpha}\right)^{2}+ \\
& +C_{\alpha \alpha \alpha} \mathrm{R} T /\left(V / x_{\alpha}\right)^{3}, \quad \alpha=1,2,3
\end{aligned}
$$

It also holds that classical partial pressures $\mathrm{B}$, denoted $P_{\alpha}{ }^{B}$, can be obtained from (1)

$$
P_{\alpha}^{B}=x_{\alpha} P, \quad \alpha=1,2,3
$$

Tables 1 and 2 present the thermodynamic partial pressures $P_{\alpha}$ and the classical partial pressures $P_{\alpha}{ }^{A}, P_{\alpha}{ }^{B}$ calculated, as explained above, for ternary mixture $\mathrm{CH}_{4}(1)-\mathrm{C}_{2} \mathrm{H}_{6}(2)-\mathrm{CO}_{2}(3)$ at temperature $T=320 \mathrm{~K}$, composition $x_{1}=0.3, x_{2}=0.3, x_{3}=0.4$ and two (total) pressures, $P=5 \mathrm{MPa}$ and $P=10 \mathrm{MPa}$.

Because at low pressures state equation (18) converges to an ideal gas mixture (cf. (17)), all partial pressures converge to ideal gas pressure B, e.g. calculation of the same system at $P=0.1 \mathrm{MPa}$ gave relations $P_{1}=P_{1}^{A}=P_{1}^{B}=P_{2}=P_{2}^{A}=P_{2}^{B}=0.030 \mathrm{MPa}$, $P_{3}=P_{3}^{A}=P_{3}^{B}=0.040 \mathrm{MPa}$ (with the precision of data shown in Tables 1 and 2).

In addition to a ternary gas mixture, we used a binary equimolar mixture of methane (1) and carbon 
Tab. 3. Pressure $P=10 \mathrm{MPa}$, temperature $T=320 \mathrm{~K}$, molar volume $V=204.7 \mathrm{~cm}^{3} / \mathrm{mol}$, compresibility factor $P V / \mathrm{R} T=0.76947$, virial coefficients $B=-61.94 \mathrm{~cm}^{3} / \mathrm{mol}, C=3018 \mathrm{~cm}^{6} / \mathrm{mol}^{2}$, pressures in $\mathrm{MPa}$, sum $=$ sum of pressures.

\begin{tabular}{lccc}
\hline Constituents & $\mathrm{CH}_{4}(1)$ & $\mathrm{CO}_{2}(3)$ & sum \\
\hline molar fractions $x_{\alpha}$ & 0.5000 & 0.5000 & ---- \\
partial molar volumes $V_{\alpha} \mathrm{cm}^{3} / \mathrm{mol}$ & 253.4 & 156.0 & --- \\
thermodynamic partial pressures $P_{\alpha}$ & 6.186 & 3.814 & 10.000 \\
A partial pressures $P_{\alpha}{ }^{A}$ & 6.026 & 5.010 & 11.036 \\
B partial pressures $P_{\alpha}^{B}$ & 5.000 & 5.000 & 10.000 \\
\hline
\end{tabular}

Tab. 4. System $\mathrm{LiOH}(1)-\mathrm{H}_{2} \mathrm{O}(2)$ at $20^{\circ} \mathrm{C}$ and atmospheric pressure $P=101325 \mathrm{~Pa}$. The dimensions $\mathrm{cm}^{3} / \mathrm{g}$ for specific volumes, $\mathrm{g} / \mathrm{cm}^{3}$ for densities, and $\mathrm{Pa}$ for pressures are used.

\begin{tabular}{ccccrrrrrr}
\hline$w_{1}$ & $\rho$ & $v$ & $-\partial \tilde{v} / \partial w_{1}$ & \multicolumn{1}{c}{$v_{1}$} & \multicolumn{1}{c}{$v_{2}$} & \multicolumn{1}{c}{$P_{1}$} & \multicolumn{1}{c}{$P_{2}$} & $P_{1}^{B}$ & $P^{B}$ \\
\hline 0 & 0.9982 & 1.0018 & 1.2903 & -0.2885 & 1.0018 & 0 & 101325 & 0 & 101325 \\
0.01 & 1.0103 & 0.9898 & 1.1488 & -0.1475 & 1.0013 & -151 & 101476 & 764 & 100561 \\
0.02 & 1.0218 & 0.9787 & 1.0884 & -0.0880 & 1.0004 & -182 & 101507 & 1532 & 99793 \\
0.04 & 1.0440 & 0.9578 & 0.9999 & -0.0020 & 0.9978 & -9 & 101334 & 3079 & 98246 \\
0.06 & 1.0655 & 0.9386 & 0.9289 & 0.0654 & 0.9943 & 423 & 100901 & 4642 & 96683 \\
0.08 & 1.0862 & 0.9206 & 0.8667 & 0.1232 & 0.9899 & 1085 & 100240 & 6221 & 95104 \\
0.10 & 1.1063 & 0.9038 & 0.8101 & 0.1747 & 0.9849 & 1959 & 99366 & 7815 & 93510 \\
\hline
\end{tabular}

dioxide (3) at a constant temperature of $T=320 \mathrm{~K}$. In this case the state equation follows from (18), (19), (20) with $x_{2} \equiv 0, x_{3}=1-x_{1}$ expressed as

$$
P=\mathrm{R} T / V+B \mathrm{R} T / V^{2}+C \mathrm{R} T / V^{3}=P\left(T, V, x_{1}\right)
$$

where now (with corresponding values (21), (22))

$$
\begin{gathered}
B=B_{11} x_{1}^{2}+B_{33} x_{3}^{2}+2 B_{13} x_{1} x_{3} \\
C=C_{111} x_{1}^{3}+C_{333} x_{3}^{3}+3 C_{113} x_{1}^{2} x_{3}+3 C_{133} x_{1} x_{3}^{2}
\end{gathered}
$$

As for the ternary gas mixture, for each pressure $P$ and composition (given by $x_{1} ; x_{3}=1-x_{1}$ ), we calculated the molar volume $V=\bar{V}\left(T, P, x_{1}\right)$, partial molar volumes $V_{\alpha}$, concentrations $c_{\alpha}$, and, using (5), (14), the thermodynamic partial pressures $P_{\alpha}(\alpha=1,3)$. The results at $T=320 \mathrm{~K}$, (total) pressure $P=10 \mathrm{MPa}$, and composition $x_{1}=0.5$ are displayed in Table 3, which, again for comparison purposes, also includes classical partial pressures A and B calculated (for $\alpha=1,3$ ) from (23) and (24) respectively.

The dependence of partial pressures on composition $x_{1}$ in the binary system $\mathrm{CH}_{4}(1)-\mathrm{CO}_{2}(3)$ at a temperature of $T=320 \mathrm{~K}$ and a (total) pressure of $P=10 \mathrm{MPa}$ is demonstrated in Fig. 1 (which describes the results for approximately 200 compositions).

Again, in the limit of low pressures we obtained the same partial pressures as for an ideal gas mixture (cf. (17)), e.g. calculation of the same system at $P=0.1 \mathrm{MPa}$ gave $P_{1}=P_{1}^{A}=P_{1}^{B}=P_{3}=P_{3}^{A}=P_{3}^{B}=$ $=0.050 \mathrm{MPa}$ (with the precision of data shown in Table 3). In this limit also both triples of partial pressures in Fig. 1 converge to lines 7 and 8, thus describing ideal gas with partial pressures $P_{\alpha}{ }^{B}$.

(Zhang et al. 1992) determined the state equation for the binary mixture $\mathrm{He}(1)-\mathrm{N}_{2}(2)$ at $25^{\circ} \mathrm{C}$ in the pressure range of 200-1000 $\mathrm{MPa}$. From this data, the thermodynamic partial pressures were calculated by similar way (Samohýl V. 2007). For example, for the equimolar mixture at $1000 \mathrm{MPa}, P_{1}=290 \mathrm{MPa}$ (i.e. $P_{2}=710 \mathrm{MPa}$ ) while $P_{1}^{B}=500 \mathrm{MPa}$ (due to the limited validity of the state equation at low pressures, partial pressures A could not be calculated).

For the calculation of thermodynamic partial pressures in a liquid mixture we chose the binary system $\mathrm{LiOH}(1)-\mathrm{H}_{2} \mathrm{O}(2)$ using the known densities (Söhnel and Novotný 1983) of this aqueous solution at $20{ }^{\circ} \mathrm{C}$ and atmospheric pressure (we used standard pressure, $101325 \mathrm{~Pa}$ ) (Almost the same results were obtained by (Samohýl V. 2007) with a rougher estimate of the derivatives (37) using the data from (d'Ans-Lax 1967).). Such a system is interesting because it involves negative partial molar volumes in diluted solutions. In this case, using (5), (14), it is possible to obtain negative thermodynamic partial pressures for $\mathrm{LiOH}(1)$ (because the total pressure is positive this negativeness is compensated by the higher thermodynamic partial pressure of water(2), cf. (4)), see Table 4 and Fig. 2.

According to (Söhnel and Novotný 1983) the density $\rho$ (in $\mathrm{g} / \mathrm{dm}^{3}$ ) of a solution of $\mathrm{LiOH}(1)$ in water $(2)$ at a constant temperature $t\left(\right.$ in ${ }^{\circ} \mathrm{C}$ ) and pressure $P=101325 \mathrm{~Pa}$, depends on the molar concentration $c_{1}$ (in $\mathrm{mol} / \mathrm{dm}^{3}$ ) of $\mathrm{LiOH}(1)$ as follows (see (Söhnel and Novotný 1983), eqs 45, 20) 
(In (Söhnel and Novotný 1983) the dimensions $\mathrm{kg} / \mathrm{m}^{3}$ and $\mathrm{kmol} / \mathrm{m}^{3}$ are used for densities and molar concentrations respectively. The numerical values calculated here and in (Söhnel and Novotný 1983) are identical. Correspondingly, we use molar masses in $\mathrm{g} / \mathrm{mol}$.):

$$
\rho=\rho_{0}+G c_{1}+H c_{1}^{3 / 2}
$$

In the following relations, $\rho_{0}$ is the density (in $\mathrm{g} / \mathrm{dm}^{3}$ ) of pure water (2), and the coefficients $G, H$ are dependent on temperature $t$ :

$$
\begin{gathered}
\rho_{0}=999.65+2.0438 t / 10-6.1744 t^{3 / 2} / 100 \\
G=\mathcal{A}+\mathcal{B} t+\mathcal{C} t^{2}, H=\mathcal{D}+\mathcal{E} t+\mathcal{F} t^{2}
\end{gathered}
$$

For the $\mathrm{LiOH}-\mathrm{H}_{2} \mathrm{O}$ system, the constants $\mathcal{A}, \mathcal{B}, \mathcal{C}, \mathcal{D}$, $\mathcal{E}, \mathcal{F}$ have the following values (Söhnel and Novotný 1983) p. 106 :

$$
\begin{aligned}
& \mathcal{A}=30.16, \mathcal{B}=0.04827, \mathcal{C}=-6.976 \times 10^{-4}, \\
& \mathcal{D}=-2.786, \mathcal{E}=-0.04538, \mathcal{F}=5.916 \times 10^{-4}
\end{aligned}
$$

Therefore at temperature $t=20{ }^{\circ} \mathrm{C}$, the following values are obtained for the density of pure water and the coefficients $G, H$ :

$$
\begin{gathered}
\rho_{0}=998,215 \mathrm{~g} / \mathrm{dm}^{3} \\
G=30.8464 \mathrm{~g} / \mathrm{mol}, \\
H=-3.45696 \mathrm{~g}(\mathrm{dm} / \mathrm{mol})^{3 / 2}
\end{gathered}
$$

Using (2), (10) we can express $c_{1}=w_{1} \rho / M_{1}$, where $M_{1}$ is the molar mass of $\mathrm{LiOH}(1)$. Inserting this into (28) we obtain the function $f\left(\rho, w_{1}\right)$, which must be identical to zero:

$$
\begin{aligned}
& f\left(\rho, w_{1}\right) \equiv\left(H / M_{1}^{3 / 2}\right) w_{1}^{3 / 2} \rho^{3 / 2}+ \\
& +\left(\left(G / M_{1}\right) w_{1}-1\right) \rho+\rho_{0}=0
\end{aligned}
$$

Using (32), (33) and $M_{1}=23.950 \mathrm{~g} / \mathrm{mol}$, we can calculate the dependence of $\rho$ on mass fraction $w_{1}$. From (6) we obtain the function $v=\tilde{v}\left(T, P, w_{1}\right)$, from which, using (8), (9), we calculate the partial specific volumes for $n=2$ as follows:

$$
\begin{gathered}
v_{1}=v+\left(1-w_{1}\right) \partial \tilde{v} / \partial w_{1} \\
v_{2}=v-w_{1} \partial \tilde{v} / \partial w_{1}
\end{gathered}
$$

The required derivative follows from functions (34) and (6)

$$
\begin{aligned}
& \partial \tilde{v} / \partial w_{1}=\left(1 / \rho^{2}\right)\left(\partial f / \partial w_{1}\right)(\partial f / \partial \rho) \\
& =\left(\frac{3}{2}\left(H / M_{1}^{3 / 2}\right) w_{1}^{1 / 2}+\rho^{-1 / 2} \frac{G}{M_{1}}\right) / \\
& /\left(\frac{3}{2}\left(H / M_{1}^{3 / 2}\right) \rho w_{1}^{3 / 2}+\left(\frac{G}{M_{1}} w_{1}-1\right) \rho^{1 / 2}\right)
\end{aligned}
$$

For the binary system $\mathrm{LiOH}(1)-\mathrm{H}_{2} \mathrm{O}(2)$ at a temperature of $20^{\circ} \mathrm{C}$ and pressure $P=101325 \mathrm{~Pa}$, equations (4) and (5) can be used to calculate the partial thermodynamic pressures $P_{1}$ and $P_{2}$

$$
\begin{gathered}
P_{1}=\rho_{1} v_{1} P \\
P_{2}=\rho_{2} v_{2} P=P-P_{1}
\end{gathered}
$$

The resulting values are displayed in Table 4. Repeating these calculations for approximately 200 values of $w_{1}$ (interval range $0-0.1$ ) we obtained curves 1 and 2 (in Fig. 2) for the thermodynamic partial pressures of this mixture.

While, as explained in the Introduction, it is not possible to obtain classical partial pressures $P_{\alpha}^{A}$ of type A for liquid mixtures, classical partial pressures $P_{\alpha}^{B}$ can be obtained using for the system $\mathrm{LiOH}(1)-\mathrm{H}_{2} \mathrm{O}(2)$ (at $20^{\circ} \mathrm{C}, 101325 \mathrm{~Pa}$ ). The results are displayed in Table 4 and in Fig. 2. The dependence of $P_{\alpha}^{B}$ on $w_{1}$ is nonlinear, namely

$P_{1}^{B}=P w_{1} M_{2} /\left(M_{1}+w_{1}\left(M_{2}-M_{1}\right)\right), P_{2}^{B}=P-P_{1}^{B}$

where $M_{1}$ is as above and $M_{2}=18.015 \mathrm{~g} / \mathrm{mol}$.

\section{Conclusions}

Thermodynamic partial pressures, proposed for common fluid models in rational thermodynamics, were calculated for a (real) gas mixture of methane, ethane and carbon dioxide and for a liquid mixture of lithium hydroxide in water. The results for the gas mixture were compared with those obtained using the classical definitions. All definitions, the classical definitions and the formulation we have proposed in this paper, share the known property that the values of the partial pressures merge to an ideal gas mixture under low pressure. In this paper we have also shown that thermodynamic partial pressures may have negative values in a liquid mixture of lithium hydroxide in water.

\section{Acknowledgements}

The authors wish to thank Prof. J. P. Novák for recommending the appropriate mixtures. The work was supported by the Ministry of Education, Youth and Sports of the Czech Republic, Research Project No. 6046137307.

\section{References}

d'Ans-Lax (1967) Taschenbuch für Chemiker und Physiker, 3rd ed., Vol.1, Springer Berlin.

de Groot SR, Mazur P (1962) Nonequilibrium Thermodynamics, North-Holland, Amster-dam. 
Hou H, Holste JC, Hall KR, Marsh KN, Gammon BE (1996) J. Chem. Eng. Data 41:344.

Müller I (1968) Arch.Rational Mech.Anal.28: 1.

Müller I (1985) Thermodynamics, Pitman, Boston.

Partington JR (1949) An Advanced Treatise on Physical Chemistry, Vol.I, Fundamental Principles, The Properties of Gases, Longmans, Green and Co., London.

Prausnitz JM, Lichtenhaler AW, de Azevedo EG (1999) Molecular Thermodynamics of Fluid-Phase Equilibria, 3rd ed., Prentice Hall, Upper Saddle River.

Samohýl I (1975a) Coll. Czechoslov. Chem. Commun. 40: 3409.

Samohýl I (1975b) Coll. Czechoslov. Chem. Commun. 40: 3421.

Samohýl I (1982) Racionální termodynamika chemicky reagujících směsí (Rational Thermodynamics of Chemically Reacting Mixtures), Academia, Prague.

Samohýl I (1987) Thermodynamics of Irreversible Processes in Fluid Mixtures, Teubner, Leipzig.
Samohýl I, Šilhavý M (1990) Arch. Rational Mech. Anal. 109: 299.

Samohýl I, Voňka P (2006) Arch. Mech. 58: 59.

Samohýl V (2007) M.S. Thesis, Institute of Chemical Technology, Prague.

Söhnel O, Novotný P (1983) Tabulky hustot vodných roztoků anorganických látek (Tables of Densities of Water Solutions of Inorganic Substances), Academia, Prague.

Truesdell C (1984) Rational Thermodynamics, 2nd Ed., Springer, New York,

Truesdell C, Toupin R (1960) The classical field theories, in: S. Flügge (Ed.), Handbuch der Physik III/1, Springer, Berlin.

Truesdell C (1968) Rend.Accad.Naz.Lincei 44(8): 381.

Zhang W, Biswas SN, Schouten JA (1992) Physica A182: 353.

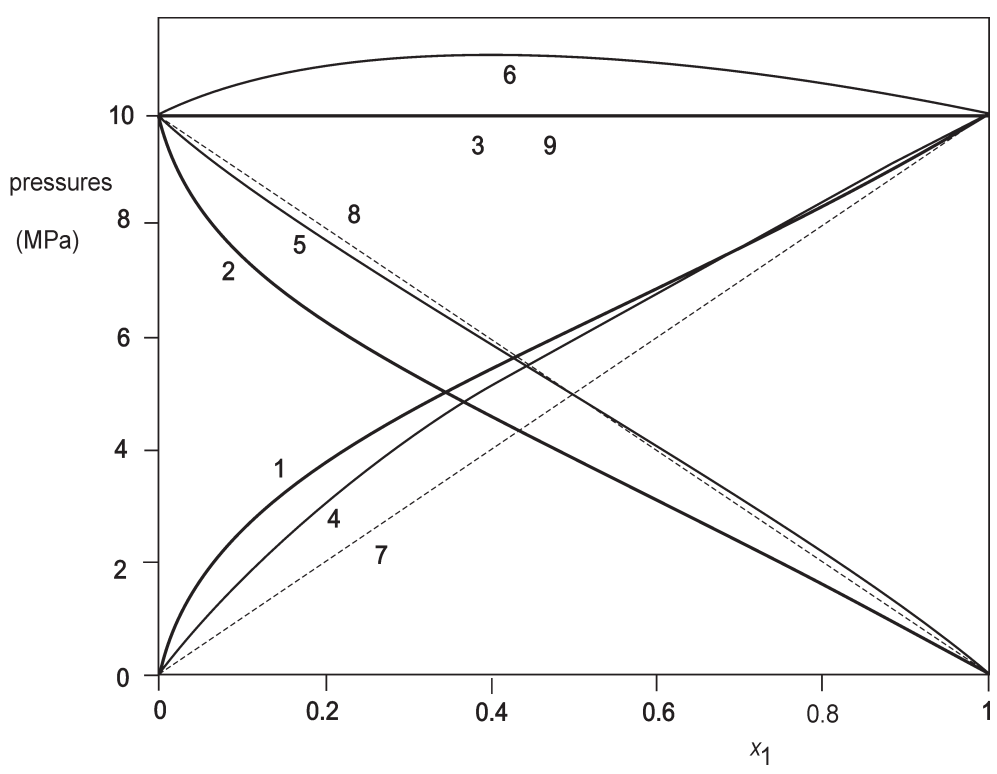

Fig. 1. The dependence of partial pressures (in MPa) on the molar fraction $x_{1}$ of methane in the binary gas mixture $\mathrm{CH}_{4}(1)-\mathrm{CO}_{2}(3)$ at a temperature of $320 \mathrm{~K}$ and total pressure $P=10 \mathrm{MPa}$.

Bold solid lines: 1 . thermodynamic partial pressure $P_{1}$ of $\mathrm{CH}_{4}(1)$; 2. thermodynamic partial pressure $P_{3}$ of $\mathrm{CO}_{2}(3) ; 3$. thermodynamic pressure $P$ of mixture : sum of both thermodynamic pressures $P_{1}+P_{3}$ (same as line 9). Solid lines: 4. classical partial pressure $P_{1}^{A}$ of $\mathrm{CH}_{4}(1)$; 5. classical partial pressure $P_{3}^{A}$ of $\mathrm{CO}_{2}(3)$; 6 . sum of classical partial pressures $P_{1}^{A}+P_{3}^{A}$.

Thin dashed lines: 7. classical partial pressure $P_{1}^{B}$ of $\mathrm{CH}_{4}(1)$; 8. classical partial pressure $P_{3}^{B}$ of $\mathrm{CO}_{2}(3) ; 9$. sum of classical partial pressures $P_{1}^{B}+P_{3}^{B}$ (the same as the line 3.). 


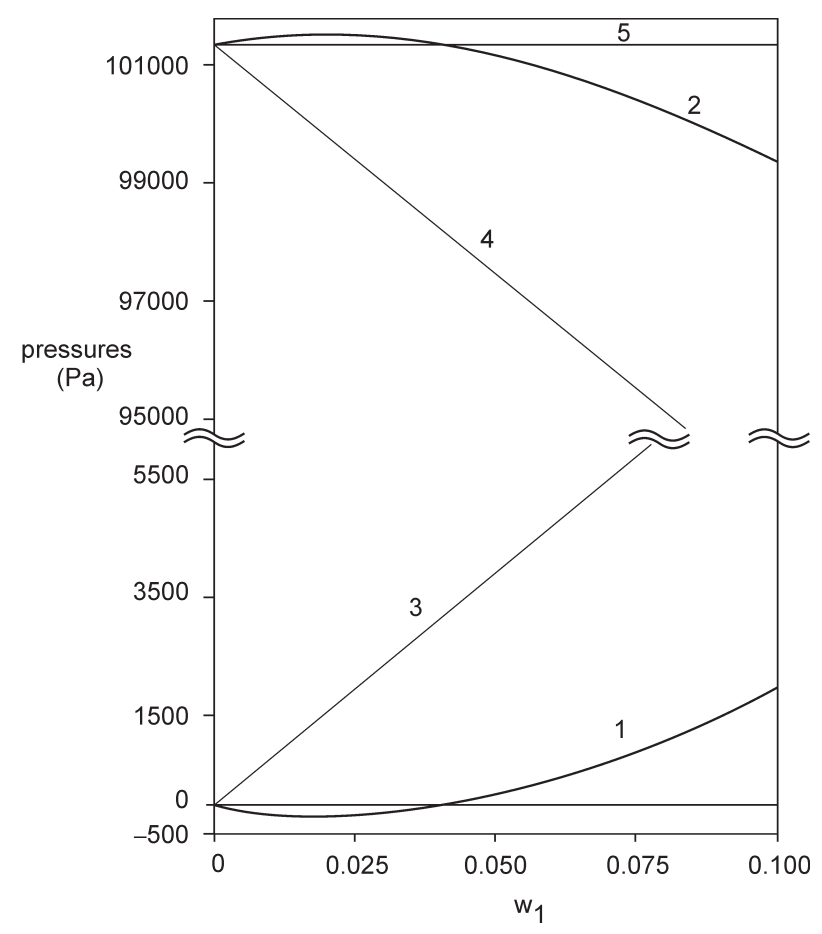

Fig. 2. The dependence of partial pressures (in $\mathrm{Pa}$ ) on the mass fraction $w_{1}$ of LiOH in the binary liquid mixture $\mathrm{LiOH}(1)-\mathrm{H}_{2} \mathrm{O}(2)$ at a temperature of $20^{\circ} \mathrm{C}$ and total (standard atmospheric) pressure $P=101325 \mathrm{~Pa}$. Solid lines: 1 . thermodynamic partial pressure $P_{1}$ of $\mathrm{LiOH}(1)$; 2. thermodynamic partial pressure $P_{2}$ of $\mathrm{H}_{2} \mathrm{O}(2) ; 5$. the sum of partial pressures of both types equals $101325 \mathrm{~Pa}$.

Thin solid lines: 3. partial pressure $P_{1}^{B}$ of $\mathrm{LiOH}(1)$; 4. partial pressure $P_{2}^{B}$ of $\mathrm{H}_{2} \mathrm{O}(2)$. 